\title{
Zonal velocity of the equatorial plasma bubbles over Kolhapur, India
}

\author{
D. P. Nade ${ }^{1}$, A. K. Sharma ${ }^{1}$, S. S. Nikte ${ }^{1}$, P. T. Patil ${ }^{2}$, R. N. Ghodpage ${ }^{2}$, M. V. Rokade ${ }^{5}$, S. Gurubaran ${ }^{3}$, A. Taori ${ }^{4}$, and \\ Y. Sahai ${ }^{6}$ \\ ${ }^{1}$ Earth and Space Science Laboratory, Department of Physics, Shivaji University, Kolhapur, India \\ ${ }^{2}$ Medium Frequency Radar, Indian Institute of Geomagnetism, Shivaji University Campus, Kolhapur, India \\ ${ }^{3}$ Indian Institute of Geomagnetism, New Panvel, Navi Mumbai, India \\ ${ }^{4}$ National Atmospheric Research Laboratory, Gadanki, India \\ ${ }^{5}$ Centre for Materials for Electronics Technology (C-MET) Hyderabad, 500051, India \\ ${ }^{6}$ Universidade do Vale do Paraiba (UNIVAP), São José dos Campos, São Paulo, Brazil
}

Correspondence to: A. K. Sharma (aks_phy@unishivaji.ac.in)

Received: 16 May 2013 - Revised: 5 October 2013 - Accepted: 25 October 2013 - Published: 22 November 2013

\begin{abstract}
This paper presents the observations of zonal drift velocities of equatorial ionospheric plasma bubbles and their comparison with model values. These velocities are determined by nightglow OI $630.0 \mathrm{~nm}$ images. The nightglow observations have been carried out from the low latitude station Kolhapur $\left(16.8^{\circ} \mathrm{N}, 74.2^{\circ} \mathrm{E} ; 10.6^{\circ} \mathrm{N}\right.$ dip lat.) during clear moonless nights. Herein we have presented the drift velocities of equatorial plasma bubbles for the period of FebruaryApril 2011. Out of 80 nights, 39 showed the occurrence of equatorial plasma bubbles (49\%). These 39 nights correspond to magnetically quiet days $(\Sigma \mathrm{Kp}<26)$. The average eastward zonal velocities $\left(112 \pm 10 \mathrm{~m} \mathrm{~s}^{-1}\right)$ of equatorial plasma bubbles increased from evening sector to 21:00 IST (Indian Standard Time = Universal Time + 05:30:00 h), reach maximum about $165 \pm 30 \mathrm{~m} \mathrm{~s}^{-1}$ and then decreases with time. The calculated velocities are in good agreement with that of recently reported values obtained with models with occasional differences; possible mechanisms of which are discussed.
\end{abstract}

Keywords. Ionosphere (Ionospheric irregularities)

\section{Introduction}

In the $\mathrm{F}$ region at low latitude, plasma irregularities have been frequently observed due to the instability processes occurring in the ionized medium. Dark patches in optical data are observed due to low electron density as compared to background density of the ionosphere, these dark patches are a manifestation of plasma irregularities. Such largescale ionospheric irregularities are also known as "equatorial plasma bubbles" (EPBs). Generally, the EPBs are generated in the bottom side of $\mathrm{F}$ region. The development and movement of these plasma structures are primarily controlled by the zonal electric fields. In the $\mathrm{E}$ and $\mathrm{F}$ region, the electric field is created by neutral winds moving across the magnetic field lines (dynamo action) (Rishbeth, 1972; Heelis et al., 1974; Kelley, 1989). The ionosphere during the night is supposed to be unstable because heavier plasma is supported by the low plasma densities at lower altitudes. In this context, after sunset, a rapid rise of the equatorial F2 layer provides a suitable opportunity for the generation of plasma instabilities because of enhancement in the upward velocity, in the evening, known as pre-reversal enhancement (PRE) (e.g., Fesen et al., 2000). Strong equatorial spread F (ESF)/EPBs typically arise soon after the PRE of the zonal electric field (Heelis et al., 1974; Fejer et al., 1999). Huang (2010) reported that more EPBs, expected during the main phase of magnetic storm, are generated more rapidly under stronger southward interplanetary magnetic field (IMF) conditions. However, all of these relate to the same physical process commonly believed to be associated with the RayleighTaylor (RT) instability (e.g., Kelley, 1989). Based on numerous ground based in situ studies, it is widely accepted that the nightglow OI $630.0 \mathrm{~nm}$ emissions are generated at low latitude F region heights $(250-300 \mathrm{~km})$. The nightglow emission 
in the $\mathrm{F}$ region at $\left({ }^{1} \mathrm{D}\right) 630.0 \mathrm{~nm}$ is governed by dissociative recombination between $\mathrm{O}_{2}^{+}$and electrons. The reaction mechanisms are given below:

$\mathrm{O}_{2}^{+}+e \rightarrow \mathrm{O}+\mathrm{O}^{*}$

$\mathrm{O}^{*} \rightarrow \mathrm{O}+h v_{(630 \mathrm{~nm})}$,

where * indicates an excited state. These mechanisms are responsible for the ionospheric OI $630.0 \mathrm{~nm}$ emission (Bates, 1992; Vlasov et al., 2005). The emission rate is, therefore, dependent on the atmospheric density $\left(\mathrm{O}_{2}\right)$ and the electron density. It means that if the $\mathrm{F}$ layer bottom height oscillates, the corresponding up and down motion will produce a decrease and an increase, respectively, in the emission rate of OI $630.0 \mathrm{~nm}$ (e.g., Takhashi et al., 2010).

Radio signals passing through EPBs can cause disruption in the navigation systems. Therefore it is of scientific interest to study the occurrence of EPBs and their propagation characteristics. The dark bands or intensity depleted regions in the OI $630.0 \mathrm{~nm}$ image are the signatures of EPBs. Sekar et al. (2007) identified plasma irregularities using coordinated VHF radar and airglow measurements from Gadanki. Several investigators have used all sky imaging system (OI $630.0 \mathrm{~nm}$ emission) to study the onset, evolution and dynamics of EPBs (e.g., Weber et al., 1980; Sahai et al., 1994; Taylor et al., 1997; Mukherjee et al., 1998; Fagundes et al., 1999; Sinha et al., 2001). Sharma et al. (2013a) presented details of change in the occurrence of EPBs, day to day, seasonal and with solar activity, using all sky images of nightglow OI $630.0 \mathrm{~nm}$ emissions over low latitude station Kolhapur. Using measurements of total electron content (TEC) and scintillations by Global Positioning System (GPS), the global longitudinal and seasonal occurrence of EPB and its vertical drifts in $\mathrm{F}$ region has been investigated by many researchers (Dashora et al., 2012; DasGupta et al., 1981; Li et al., 2008, 2012). It is also well appreciated that the there is variation in zonal plasma drift day-to-day (Mukherjee and Shetti, 2008), seasonally (Yao and Makela, 2007) and with solar activity (Sahai et al., 2012).

The zonal plasma drift speeds of equatorial nighttime plasma depletions observed using the imager aboard a highapogee IMAGE satellite during March-May 2002 had a strong longitudinal dependence and are maximum over the Indian sector (Immel et al., 2004). Martinis et al. (2003) presented studies of plasma drift using OI $630.0 \mathrm{~nm}$ measurements from South American Sector. According to them (see Table 1 of Martinis et al., 2003) the zonal plasma drifts, during night, were eastward during low magnetic activity while westward during moderate magnetic activity. The range of eastward velocity of EPBs is about $140-200 \mathrm{~m} \mathrm{~s}^{-1}$ (de Paula et al., 2002). These drifts are largest at about 21:00-22:00 local time (LT) and they decrease towards sunrise.

In this paper we present the zonal drift velocity of EPBs from observations made by using all sky imager (ASI) located at Kolhapur in India. These calculated drift velocities are compared with that of the model values presented by England and Immel (2012). The drift velocities of the EPBs and their variation with seasons and their dependence on geomagnetic and solar activities, are also discussed.

\section{Instrumentation}

Regular nightglow observations of OI $630.0 \mathrm{~nm}$ were made using ASI during clear moonless nights from Kolhapur. This ASI (make: Keo Scientific Ltd. Canada) was installed at Shivaji University Campus, Kolhapur, under the scientific collaborative program between Shivaji University, Kolhapur, (S.U.K.) and Indian Institute of Geomagnetism (I.I.G.), Navi Mumbai, India, to measures nightglow emissions. This system can be operated for \pm 7 ( \pm seven) nights around a new moon night. There are three interference filters, with center wavelengths of OI $630.0 \mathrm{~nm}$, OI $557.7 \mathrm{~nm}$ and $\mathrm{OH}$ Meinel bands (720.0-910.0 nm) having exposures time of typically $120 \mathrm{~s}, 120 \mathrm{~s}$ and $90 \mathrm{~s}$, respectively, are used to study the ionospheric dynamics.

For present data, high resolution $(1024 \times 1024$ pixels) CCD $(13.3 \mathrm{~mm} \times 13.3 \mathrm{~mm}$ to $27.6 \mathrm{~mm} \times 27.6 \mathrm{~mm})$, back-illuminated array with a pixel depth of 16 bit-based ASI has been used. The quantum efficiency of CCD is $>90 \%$ for OI $630.0 \mathrm{~nm}$ emissions. Low dark current ( 0.5 electrons $/ \mathrm{pixel} / \mathrm{sec})$, with low readout noise and high linearity of ASI, is useful to observe nightglow emissions for longer time periods. The $180^{\circ}$ field of view (FOV) fish eye lens (f/4 Mamiya RB67) having a focal length of $24 \mathrm{~mm}$ and a tele-centric len system are used to collect the signal coming through the ionosphere, with high signal-to-noise ratio. Before the operation, dark counts are reduced by thermoelectrically cooling of the CCD to $-80^{\circ} \mathrm{C}$. Nade et al. (2012) have given the detail of experimental setup.

\section{Observations and method}

Kolhapur $\left(16.8^{\circ} \mathrm{N}, 74.2^{\circ}\right.$; dip lat $\left.10.6^{\circ} \mathrm{N}\right)$ is located in between the dip equator and northern crest of the equatorial ionization anomaly (EIA) and thus it has an electro-dynamical importance in $\mathrm{E}$ and $\mathrm{F}$ region coupling processes. The location of the Kolhapur and area covered by ASI at an altitude $250 \mathrm{~km}$ over Kolhapur is shown in Fig. 1. We have taken data of OI $630.0 \mathrm{~nm}$ images for the period of October 2010-May 2011. Images have been processed using method described by Sharma et al. (2013b), for flat field correction, background illuminations and identification of stationary features. They reported an "addition method" for flat fielding correction. The average image was obtained by averaging data of an hour and then this image was subtracted from each image of an hour data. Due to this process we can easily identify EPB's in OI $630.0 \mathrm{~nm}$ images. Figure 2 illustrates the sequence of processed images of OI $630.0 \mathrm{~nm}$, taken on 1-2 April 2011 from 20:55:14 IST to 22:21:37 IST 


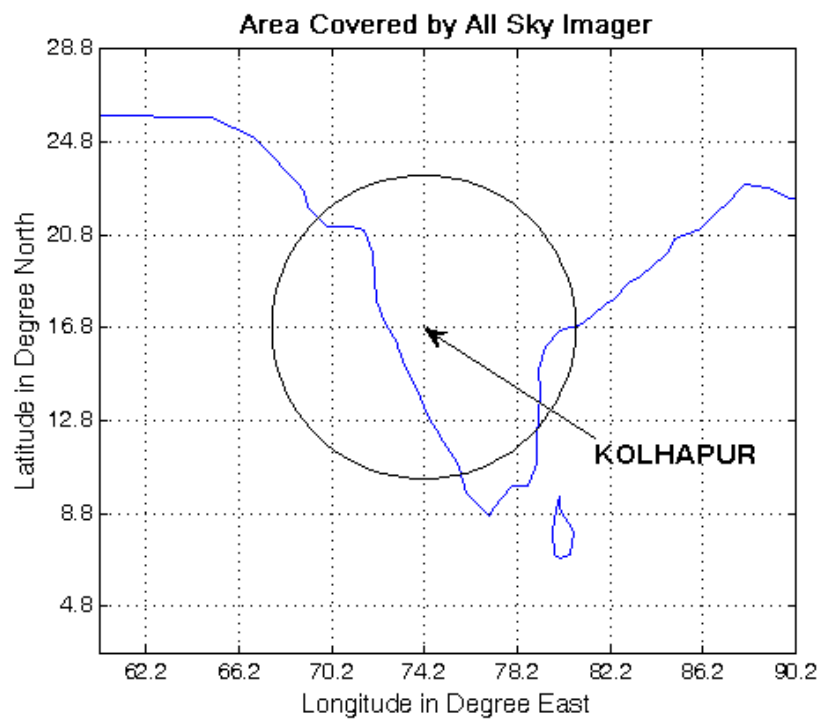

Fig. 1. The location of the Kolhapur and area covered by ASI (FOV $140^{\circ}$ ) at an altitude $250 \mathrm{~km}$ where $630.0 \mathrm{~nm}$ emissions are generated.

$($ Indian Standard Time $=$ Universal Time $+05: 30: 00 \mathrm{~h})$. The details of image processing are described by Sharma et al. (2013b).

The zonal drift velocity of EPB can be calculated by comparing its positions in consecutive images to find the longitudinal offset and dividing it by the time difference between images (Makela and Kelley, 2003; Makela et al., 2005). However Pimenta et al. (2001) proposed the "scanning method" to calculate drift velocities of EPBs from OI $630.0 \mathrm{~nm}$ images. Using this, we have first scanned the optical images through the zenith $\left(16.8^{\circ} \mathrm{N}\right)$ from east to west to obtain a cross section of the depletion patterns for each EPB. Then, these cross-sectional scans are subjected to further analysis. A succession of spatial space and time shifts leads to a zonal velocity versus local time relation for EPB. Herein we have taken only those images having EPBs at or near the zenith (in $100^{\circ} \mathrm{FOV}$ ).

Calculation of zonal drift velocities from OI $630.0 \mathrm{~nm}$ using this method is illustrated in Fig. 3. In Fig. 3, the upper panel a shows three images of OI $630.0 \mathrm{~nm}$, taken on 34 April 2011 at 21:53:37 IST, 21:58:53 IST and 22:04:09 IST. The middle panels show the east-west scan of depletion region obtained in these three images, the lower panel indicates east-west scanned data smoothed by 50 points average and pink arrows (in upward directions) indicates the center of EPBs. The east-west scanned data are smoothed by 50 points average to recognize the boundaries of EPBs. In nightglow OI $630.0 \mathrm{~nm}$ intensity (arb. unit) plot, the pink arrows (in upward directions) indicate the motion of center of EPBs from west to east. The spatial displacements of these EPBs are determined by this method and then divided by

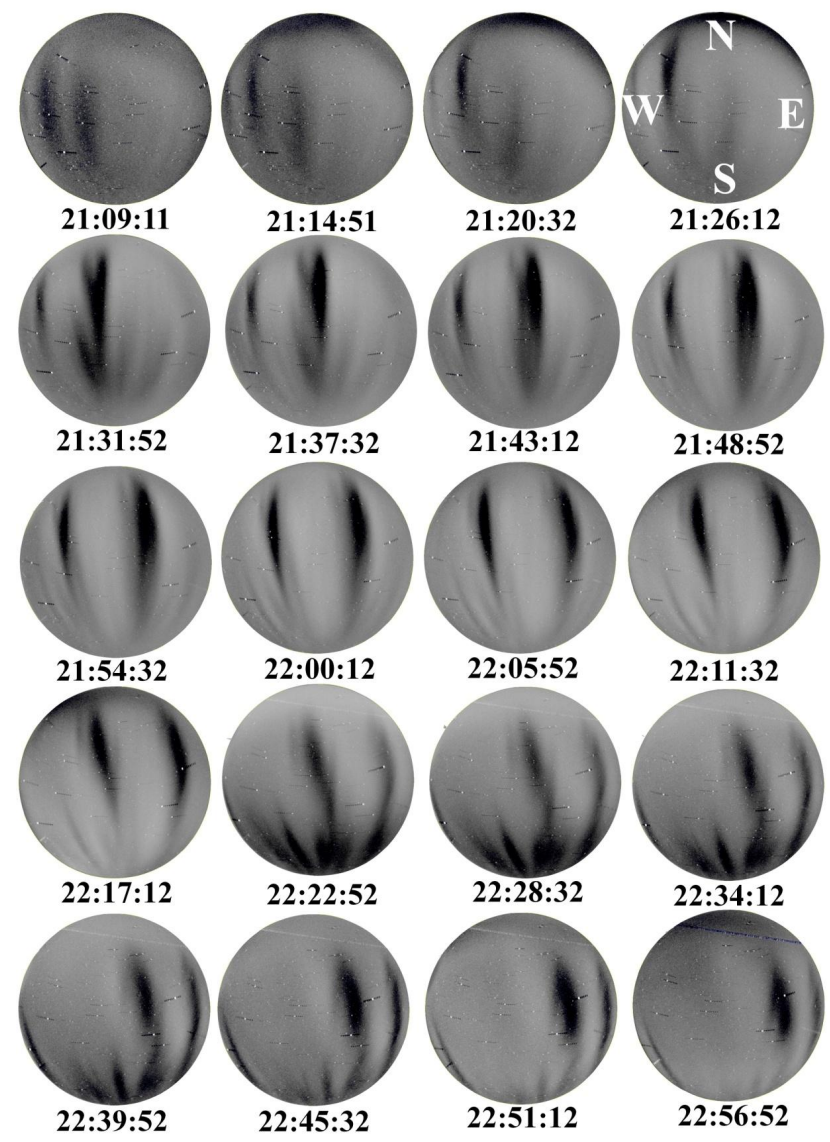

Fig. 2. A few sequences of OI $630.0 \mathrm{~nm}$ images taken on 12 April 2011 by ASI from Kolhapur.

time (time difference between these images). Thus the velocities of EPBs are determined.

Pimenta et al. (2001) reported the method to linearise images with an appropriate geographic co-ordinate system (Garcia et al., 1997) for comparing the east-west intensity variations in consecutive images. Herein we have converted pixel numbers into kilometers using formula developed by Sharma et al. (2013b) as,

$\psi=\cos ^{-1}\left(\frac{R_{\mathrm{h}}^{2}+R^{2}-r^{2}}{2 R_{\mathrm{h}} R}\right)$

Arc $=$ Radius $\times$ Angle $=R_{\mathrm{h}} \times \psi$,

where $\psi$ is earth centered angle, $R$ the mean radius of the earth, $R_{\mathrm{h}}$ the sum of mean radius of the earth and height of airglow emission layer and $r$ the distance between location of imager and signature of EPB in sky, obtained in OI $630.0 \mathrm{~nm}$ images. For the present study, we have assumed that the altitude of airglow emission is about $250 \mathrm{~km}$ for the OI $630.0 \mathrm{~nm}$ emission. The variability in the electron density is occurring at about $250 \pm 20 \mathrm{~km}$ altitude. This is represented by Clemesha and Takahashi (1993) from measurements of nightglow 

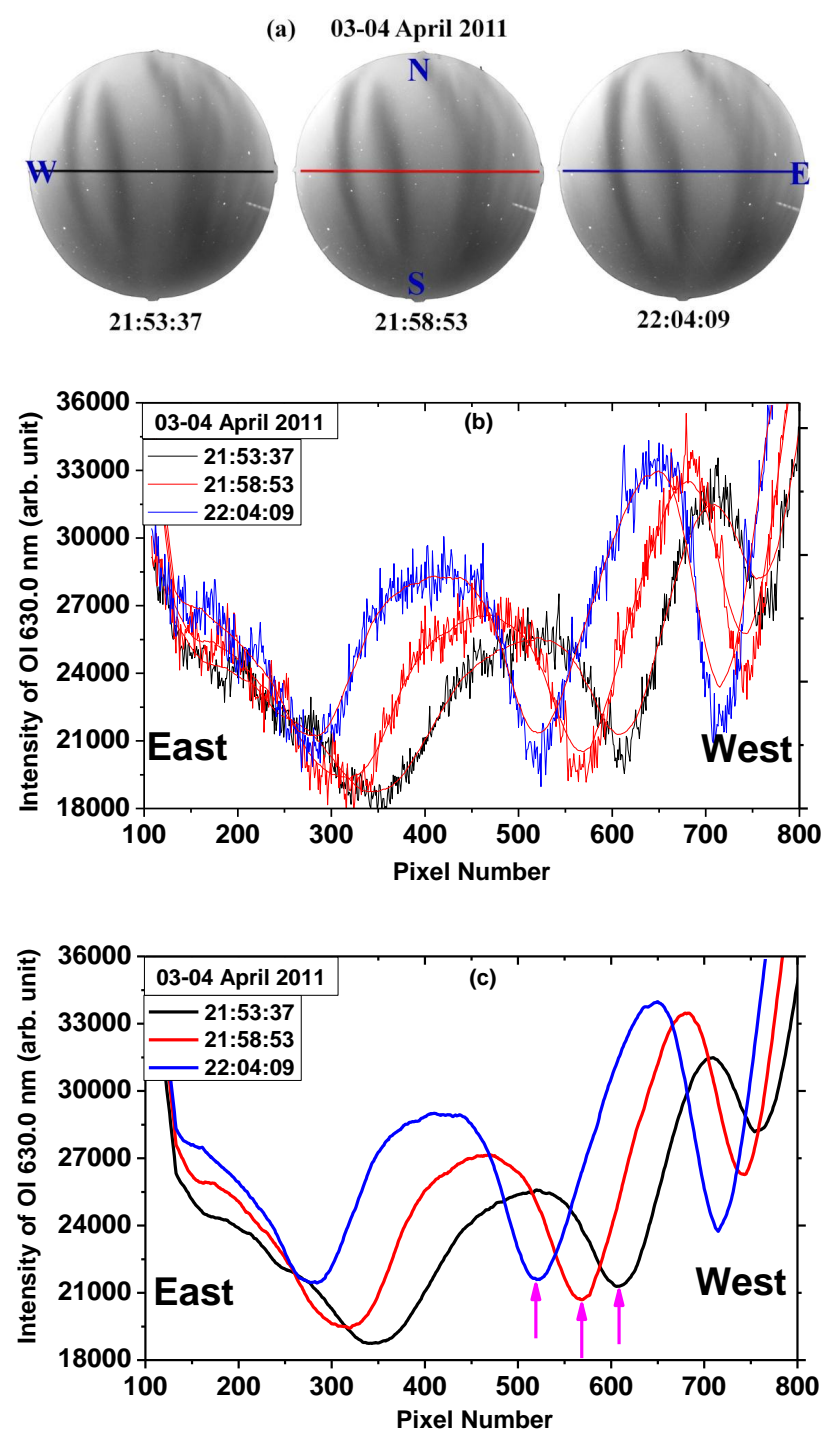

Fig. 3. The drift velocities of EPBs are determined from OI $630.0 \mathrm{~nm}$ using a scanning method. (a) shows images of OI $630.0 \mathrm{~nm}$ taken by ASI from Kolhapur at 21:53:37, 21:58:53 and 22:04:09 IST on 3-4 April 2011. (b) shows east-west scan of depletion (EPBs) showing in (a). (c) shows east-west scanned data smoothed by 50 points averaged and yellow arrows (in upward directions) indicates the center of EPB.

OI $630 \mathrm{~nm}$ image. Taori et al. (2013) also reported that the emission height of OI $630.0 \mathrm{~nm}$ is about $250 \mathrm{~km}$. Pimenta et al. (2003) and Sekar et al. (2007) reported that the nightglow OI $630.0 \mathrm{~nm}$ emission was generated at thermospheric altitude of about $250 \mathrm{~km}$.

We have determined motion of western wall, center and eastern wall of EPB using scanning and geometry methods for all nights having an occurrence of EPBs. Herein we have taken the average of these motions to determine the value of zonal plasma drift velocities.

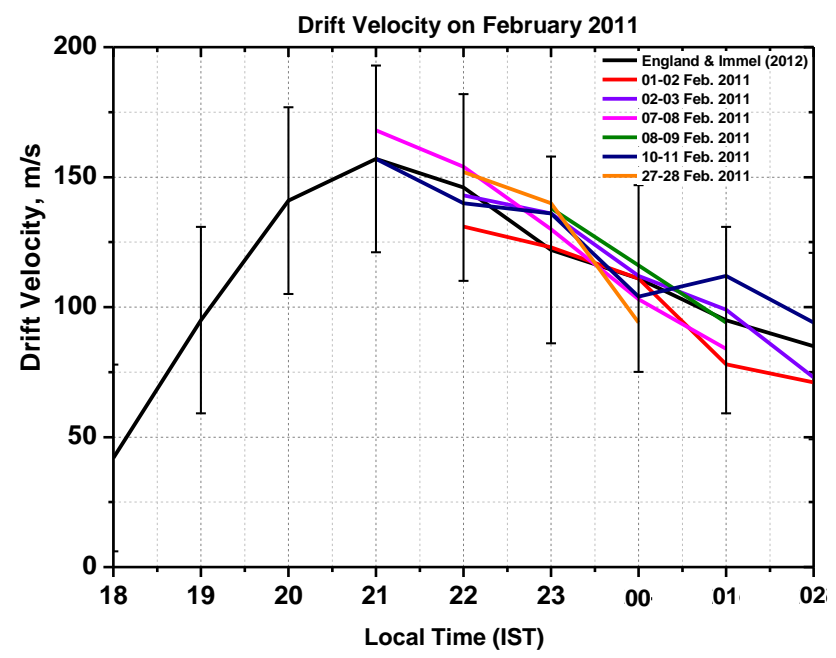

Fig. 4. The daily mean zonal drift velocities of EPBs compared with values of the empirical model for the period of February 2011.

\section{Results}

Using the methods described earlier, we have calculated plasma drift velocities for 80 nights in the period October 2010 to May 2011. Out of 80 nights, 39 nights show occurrence of EPBs (49\%). These 39 nights correspond to magnetically quiet days. As the increase in geomagnetic activity may take many hours to influence drift velocities (Fejer et al., 2005). The magnetic activity is indicated with the $\Sigma \mathrm{Kp}$ index. Herein, we have considered, the day with $\Sigma \mathrm{Kp}$ index greater than or equal to 26 to be magnetically "disturbed" days. Using this criterion, the effects of geomagnetic activities on drift velocity of EPBs is studied. Each night contained 80-110 images taken between 19:30 IST and 05:00 IST. The values of velocities of EPBs for the period of hour are centered on the $15 \mathrm{~min}$ and $45 \mathrm{~min}$ marks of each hour and average has been considered. Out of total 3753 images, 561 images show clear EPBs. Only those images having EPBs at zenith or near zenith have been taken into account. In the present paper, variations in the drift velocities of EPBs are presented of those nights having more than three hour images with clear signatures of EPBs.

Figures 4-6 show the comparison of the mean zonal drift velocities of EPBs as a function of time with model values (England and Immel, 2012) for the period of February to April 2011, respectively, over Kolhapur region. The average zonal velocities of ionospheric EPB for these periods are eastward and reach a maximum to $165 \pm 30 \mathrm{~m} \mathrm{~s}^{-1}$ (averaged value) around 20:30-21:30 IST and decreasing with time. Our results are in good agreement with the model values for the period February to April 2011 (Figs. 4 and 6), however, it is higher than that of model values for March 2011 (Fig. 5). The $\Sigma \mathrm{Kp}$ index and $F_{10.7 \mathrm{~cm}}$ are obtained from http://sec.noaa.gov. It is noted from Table 1 that the value of $F_{10.7 \mathrm{~cm}}$ is higher in March 2010 than in February and 
Table 1. The daily $\Sigma \mathrm{Kp}$ index and $F_{10.7 \mathrm{~cm}}$ flux for the period of February-April 2011.

\begin{tabular}{|c|c|c|c|c|c|c|c|c|}
\hline \multicolumn{3}{|c|}{ February 2011} & \multicolumn{3}{|c|}{ March 2011} & \multicolumn{3}{|c|}{ April 2011} \\
\hline Date & $F_{10.7 \mathrm{~cm}}$ & $\begin{array}{r}\Sigma \mathrm{Kp} \\
\text { Index }\end{array}$ & Date & $F_{10.7 \mathrm{~cm}}$ & $\begin{array}{r}\Sigma \mathrm{Kp} \\
\text { Index }\end{array}$ & Date & $F_{10.7 \mathrm{~cm}}$ & $\begin{array}{r}\Sigma \mathrm{Kp} \\
\text { Index }\end{array}$ \\
\hline $1 / 2 / 2011$ & 80 & 19 & $2 / 3 / 2011$ & 113 & 26 & $1 / 4 / 2011$ & 109 & 19 \\
\hline $2 / 2 / 2011$ & 79 & 13 & $6 / 3 / 2011$ & 143 & 11 & $3 / 4 / 2011$ & 114 & 25 \\
\hline $7 / 2 / 2011$ & 82 & 8 & $7 / 3 / 2011$ & 153 & 17 & 4/4/2011 & 113 & 12 \\
\hline $8 / 2 / 2011$ & 90 & 9 & $8 / 3 / 2011$ & 155 & 10 & $5 / 4 / 2011$ & 109 & 12 \\
\hline $10 / 2 / 2011$ & 91 & 9 & $27 / 3 / 2011$ & 117 & 3 & $6 / 4 / 2011$ & 117 & 29 \\
\hline \multirow[t]{4}{*}{$27 / 2 / 2011$} & 90 & 3 & $28 / 3 / 2011$ & 119 & 5 & 7/4/2011 & 112 & 9 \\
\hline & & & $29 / 3 / 2011$ & 116 & 5 & $26 / 4 / 2011$ & 109 & 3 \\
\hline & & & $30 / 3 / 2011$ & 118 & 7 & & & \\
\hline & & & $31 / 3 / 2011$ & 113 & 6 & & & \\
\hline
\end{tabular}

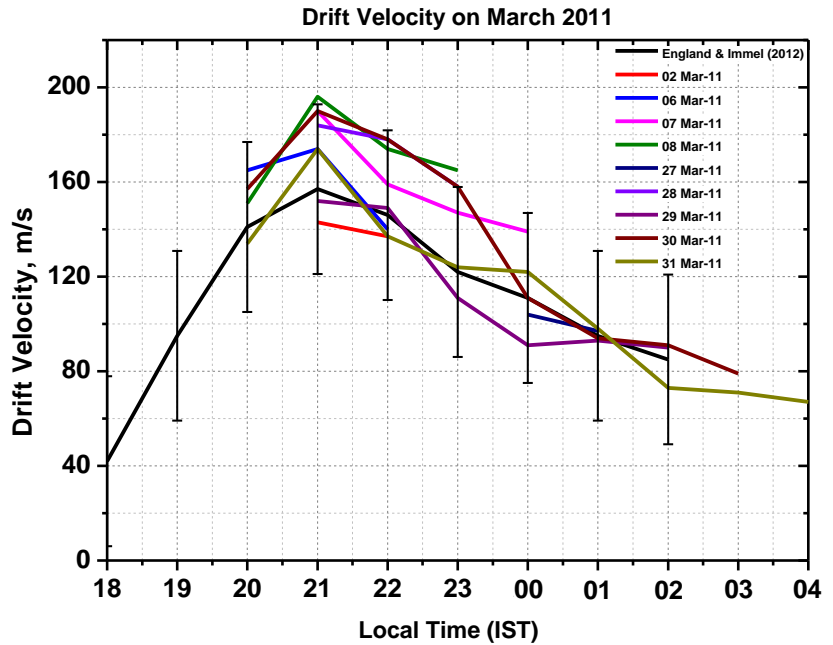

Fig. 5. The daily mean zonal drift velocities of EPBs compared with values of the empirical model for the period of March 2011.

April 2010. The period, February to April 2010 has been magnetically quiet, as the averaged value of $\Sigma \mathrm{Kp}$ index have been 11.91. This difference suggests that the variation in zonal drift velocity of EPB depends on the solar activity $\left(F_{10.7} \mathrm{~cm}\right)$. Figure 7 shows monthly averaged values of velocity for these three months and standard deviations of model values. It is also clear from Fig. 7, that the magnitude of averaged zonal drift velocities are more than that of the model values during the evening time (up to 21:00 IST) and less after 21:00 IST.

\section{Discussion}

In this work we have presented zonal drift velocities of ionospheric EPBs calculated by using recently developed techniques. The mean velocity of EPBs in evening time is about $112 \pm 10 \mathrm{~m} \mathrm{~s}^{-1}$ and increases to $165 \pm 30 \mathrm{~m} \mathrm{~s}^{-1}$ at around 21:00 IST and then decreases with time. De Paula et

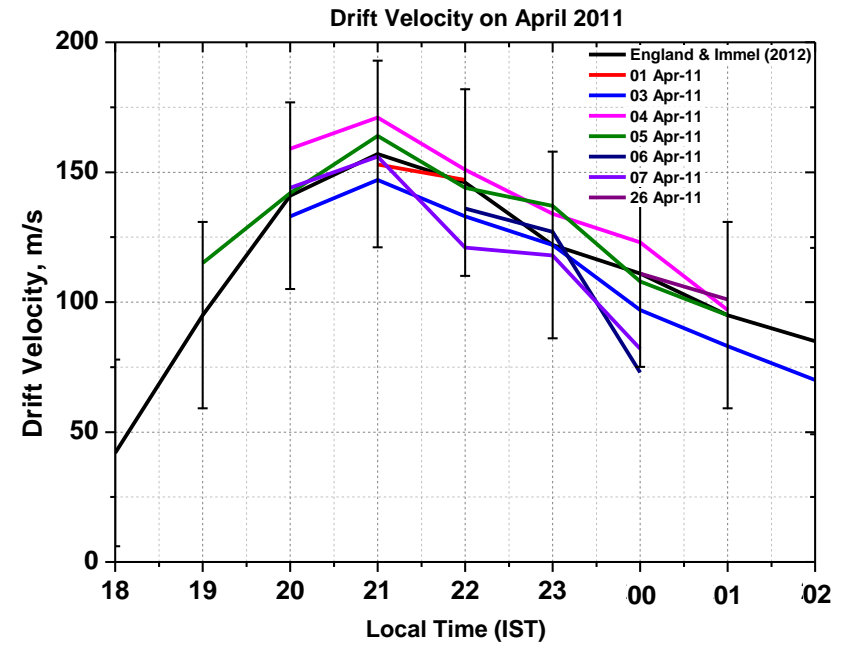

Fig. 6. The daily mean zonal drift velocities of EPBs compared with values of the empirical model for the period of April 2011.

al. (2002) reported that the eastward zonal drift velocities of irregularity were $\sim 160 \mathrm{~m} \mathrm{~s}^{-1}$ at 20:00 LT and $\sim 140 \mathrm{~m} \mathrm{~s}^{-1}$ at midnight (00:00 LT). The temporal evolution characteristics of drift velocity over Kolhapur are very similar to that of obtained from different locations. However velocities of EPBs are smaller than that of the obtained in Brazilian sector. There is a large variability in the calculated zonal drift velocity mainly in the pre-midnight sector, which decreases after midnight by reverse fountain effect which increases the drag. The nature of zonal velocities is in good agreement with model values and within the standard deviations. Our results are in overall agreement with the previous studies in which the calculated average zonal velocity of EPB was found to be $\sim 140 \mathrm{~m} \mathrm{~s}^{-1}$ (Mukherjee et al., 1998). In Indian region, by simultaneous observations of VHF scintillations from Ujjain and Bhopal, Kumar et al. (1995) reported that the eastward drift velocities of ionospheric irregularities were decreasing from about $180 \mathrm{~m} \mathrm{~s}^{-1}$ to $55 \mathrm{~m} \mathrm{~s}^{-1}$ during the course of night. 


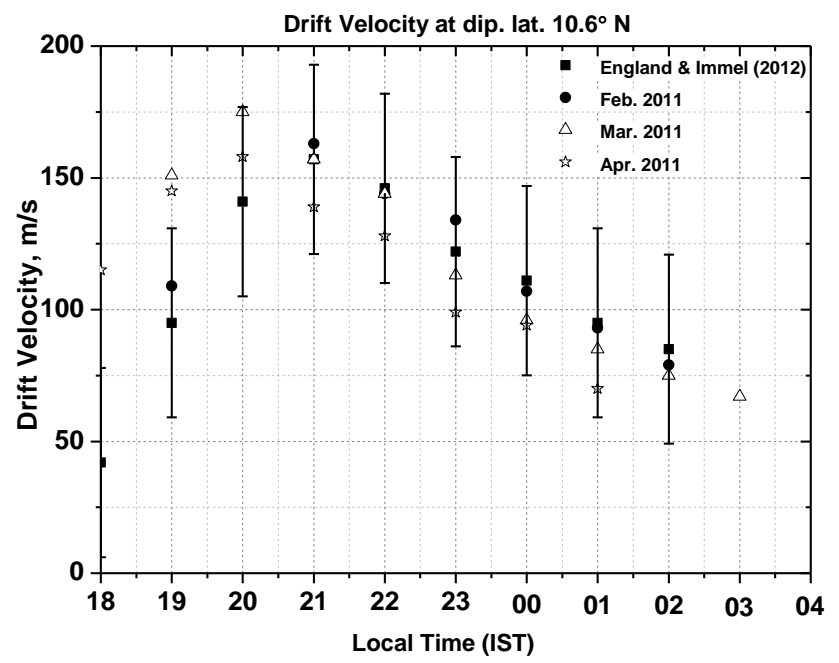

Fig. 7. The monthly mean zonal drift velocities of EPBs compared with values of the empirical model for the months of February, March and April 2011.

Taori et al. (2013) also found that the drift velocity of plasma depletion was $\sim 135 \pm 15 \mathrm{~m} \mathrm{~s}^{-1}$ by 2-D correlation analysis of OI $630.0 \mathrm{~nm}$ images over Gadanki, India.

In the present work, the calculated zonal velocities are higher than that of model values before midnight and significantly smaller afterwards. De Paula et al. (2002) reported that the eastward zonal velocities of EPBs decrease after midnight. This is because of reduction in zonal neutral wind velocities. After sunset, the growths of ionospheric plasma instabilities are driven by zonal (eastward) electric field (Fejer et al., 1999). This electric filed is mapped along the entire magnetic field line. Thus plasma is built up in the flux tube and moves with the neutral wind. However, in the low latitude region, the electric fields are generated by neutral winds (Haerendel and Eccles, 1992), which drives meridional Pedersen currents in the $\mathrm{E}$ and $\mathrm{F}$ regions. Therefore dynamo action is created in these regions. Bitten-court and Sahai (1978) reported that the ionospheric vertical plasma drift is produced by a horizontal thermospheric neutral wind at low latitudes. The intensity of this electric field is enhanced soon after sunset and decreases with time because of the reduced neutral wind velocity (Terra et al., 2004). Thus the nocturnal zonal drift of the plasma depends on the polarization of electric field in the F region which is clearly noted in our results.

We have observed that the velocity of EPB varies with solar activity $\left(F_{10.7 \mathrm{~cm}}\right)$ for magnetically quite $(\Sigma \mathrm{Kp} \leq 26)$ conditions. This aspect is also noted by few other investigators. Sobral et al. (2009) reported that a tendency of the zonal velocities of EPBs to increase almost linearly with increasing solar flux units. The thermospheric zonal wind is responsible for the motion of EPBs. The intensity of zonal wind increases due to enhanced solar thermal tide, which is represented by solar flux $\left(F_{10.7 \mathrm{~cm}}\right)$. England and Immel (2012) reported that brighter airglow emissions were created during the higher solar extreme ultra violet (EUV) flux period, 2002. Multi-mode structure of thermospheric wind, temperature and composition of thermosphere as well as electric field is responsible for this phenomenon (Deminova, 2003). Nade et al. (2012) reported that rate of occurrence of EPBs over Kolhapur region increased during higher solar EUV flux $\left(F_{10.7 \mathrm{~cm}}\right)$. It is important to note that geomagnetic storms also affect the dynamics of the low-latitude ionosphere in very significant ways (Martinis et al., 2005). During the geomagnetic storm period, occurrence of EPBs increase more than in normal period (Sahai et al., 1998). At a low latitude region, the F layer dynamo is created by various factors such as traveling ionospheric disturbances (TIDs) (Mansilla, 2003). It is also relevant to note that apart from the above, vertical coupling arising because of upward propagation of mesospheric waves (Taori et al., 2011), internal gravity waves, TIDs (Makela et al., 2010) and GPS (Dashora et al., 2012) can also be the sources observed variability in ionospheric and atmospheric parameter disturbances (Leonovich et al., 2011). However, these aspects need further investigations.

\section{Conclusions}

The nightglow OI $630.0 \mathrm{~nm}$ images have been obtained by ASI located at Kolhapur, during October 2010 to May 2011. The velocity of EPBs is calculated using method suggested by Pimenta et al. (2001) and transformed the pixel distance to actual distance using method presented by Sharma et al. (2013a). Our results are in good agreement with empirical model which is presented by England and Immel (2012).

Differences between calculated velocity and model velocity suggest something about the pre-midnight development of EPBs and variations in zonal neutral wind velocities. The velocity of EPB varies with solar activity $\left(F_{10.7} \mathrm{~cm}\right)$ for magnetically quite $(\Sigma K \mathrm{~K} \leq 26)$ conditions. The eastward average zonal velocity of EPBs increases from the evening sector $\left(112 \pm 10 \mathrm{~m} \mathrm{~s}^{-1}\right)$ to reach maximum about $165 \pm 30 \mathrm{~m} \mathrm{~s}^{-1}$ around 21:00 IST and then decreases with time over the low latitude region of Kolhapur.

Acknowledgements. Mr. D. P. Nade is thankful to DST-PURSE for research assistantship. The nightglow observations at Kolhapur are carried out under scientific collaboration between Shivaji University, Kolhapur, and Indian Institute of Geomagnetism (I.I.G.), Navi Mumbai. We also are thankful to the NOAA-GOES team for providing the data of solar and geomagnetic indices over the Internet. Mr. D. P. Nade is also thankful to Mr. R. B. Mane (Sir) (J. B. Patil High School Chipari, Kolhapur) and Miss. R. P. Pawar for useful discussion regarding the generation of EPBs.

Topical Editor R. Stoneback thanks H. Chandra and one anonymous referee for their help in evaluating this paper. 


\section{References}

Bates, D. R.: Emission of forbidden red and green lines of atomic oxygen from the nocturnal F region, Plonel. Sprrce Sci., 40, 893899, 1992.

Bitten-court, J. A. and Sahai, Y.: F region neutral winds from ionosonde measurements of $h m \mathrm{f} 2$ at low-latitude magnetic conjugate regions, J. Atmos. Terr. Phys., 40, 669-676, 1978.

Clemesha, B. R. and Takahashi, H.: Airglow studies via rocketborne photometers in Brazil, Braz. J. Geophys., 11, 139-155, 1993.

DasGupta, A., Maritra, A., and Basu, S.: Occurrence of nighttime VHF scintillations near the equatorial anomaly crest in the Indian sector, Radio Sci., 16, 1455-1458, 1981.

Dashora, N., Taori, A., and Patra, A. K.: Multi Instrument Observation of winter solstice $\mathrm{F}$ region irregularities during the low solar activity, Ind. J. Radio Space Phys., 41, 220-232, 2012.

Deminova, G. F.: Fine structure of fof 2 longitudinal distribution in the night-time low-latitude ionosphere derived from intercosmos-19 topside sounding data, Adv. Space Res., 31, 531536, 2003.

de Paula, E. R., Kantor, I. J., Sobral, J. H. A., Takahashi, H., Santana, D. C., Gobbi, D., Medeiros, A. F., Limiro, L. A. T., Kil, H., Kintner, P. M., and Taylor, M. J.: Ionospheric irregularity zonal velocities over Cachoeira Paulista. J. Atmos. Sol.-Terr. Phys., 64, 1511-1516, 2002.

England, S. L. and Immel, T. J.: An empirical model of the drift velocity of equatorial plasma depletions, J. Geophys. Res., 117, A12308, doi:10.1029/2012JA018091, 2012.

Fagundes, P. R., Sahai, Y., Batista, I. S., Abdu, M. A., Bittencourt, J. A., and Takahashi, H.: Observations of day-to-day variability in precursor signatures to equatorial F-region plasma depletions, Ann. Geophys., 17, 1053-1063, doi:10.1007/s00585-999-1053$\mathrm{x}, 1999$.

Fejer, B. G., Scherliess, L., and de Paula, E. R.: Effects of the vertical plasma drift velocity on the generation and evolution of equatorial spread F, J. Geophys. Res., 104, 19859-19870, 1999.

Fejer, B. G., de Souza, J., Santos, A. S., and Costa Pereira, A. E.: Climatology of F region zonal plasma drifts over Jicamarca, J. Geophys. Res., 110, A12310, doi:10.1029/2005JA011324, 2005.

Fesen, C. G., Roble, R. G., Richmond, A. D., Crowley, G., and Fejer, B. G.: Simulation of the pre-reversal enhancement in the lowlatitude vertical ion drifts, Geophys. Res. Lett., 27, 1851-1854, 2000.

Garcia, F. J., Taylor, M. J., and Kelley, M. C.: Two-dimensional spectral analysis of mesospheric airglow image data, Appl. Optics, 36, 7374-7385, 1997.

Haerendel, G. and Eccles, J. V.: The role of the equatorial electrojet in the evening ionosphere, J. Geophys. Res., 97, 1181-1192, 1992.

Heelis, R. A., Kendall, P. C., Moffett, R. J., and Windle, D. W.: Electrical coupling of the $\mathrm{E}$ and $\mathrm{F}$ regions and its effect on $\mathrm{F}$ region drifts and winds, Planet Space Sci., 22, 743-756, 1974.

Huang, C.-S., de La Beaujardiere, O., Pfaff, R. F., Retterer, J. M. Roddy, P. A., Hunton, D. E., Su, Y.-J., Su, S.-Y., and Rich, F. J.: Zonal drift of plasma particles inside equatorial plasma bubbles and its relation to the zonal drift of the bubble structure, J. Geophys. Res., 115, A07316, doi:10.1029/2010JA015324, 2010.

Immel, T. J., Frey, H. U., Mende, S. B., and Sagawa, E.: Global observations of the zonal drift speed of equatorial ionospheric plasma bubbles, Ann. Geophys., 22, 3099-3107, doi:10.5194/angeo-22-3099-2004, 2004.

Kelley, M. C.: The Earth's Ionosphere, Int. Geophys. Ser, 43, Academic, San Diego, Calif, 1989.

Kumar, S., Gwal, A. K., Pathan, B. M., and Rao, D. R. K.: Zonal drifts of ionospheric irregularities at temperate latitude in the Indian region, Ann. Geophys., 13, 724-729, doi:10.1007/s00585995-0724-5, 1995.

Leonovich L. A., Mikhalev, A. V., and Leonovich, V. A.: The 557.7 and $630 \mathrm{~nm}$ Atomic Oxygen Midlatitude Airglow Variations Associated with Geomagnetic Activity, Atmospheric and Oceanic Optics, 24, 396-401, 2011.

Li, G., Ning, B., Liu, L., Zhao, B., Yue, X., Su, S.-Y., and Venkatraman, S.: Correlative study of plasma bubbles, evening equatorial ionization anomaly, and equatorial pre-reversal EB drifts at solar maximum, Radio Sci., 43, RS4005, doi:10.1029/2007RS003760, 2008.

Li, G., Ning, B., Liu, L., Wan, W., Hu, L., Zhao, B., and Patra, A. K.: Equinoctial and June solstitial F region irregularities over Sanya, India, Ind. J. Radio Space Phys., 41, 184-198, 2012.

Makela, J. J. and Kelley, M. C.: Field-aligned 777.4-nm composite airglow images of equatorial plasma depletions, Geophys. Res. Lett., 30, 1442, doi:10.1029/2003GL017106, 2003.

Makela, J. J., Kelley, M. C., and Su, S.-Y.: Simultaneous observations of convective ionospheric storms: ROCSAT1 and ground-based imagers, Space Weather, 3, S12C02, doi:10.1029/2005SW000164, 2005.

Makela, J. J., Miller, E. S., and Talaat, E. R.: Nighttime medium-scale traveling ionospheric disturbances at low geomagnetic latitudes, Geophys. Res. Lett., 37, L24104, doi:10.1029/2010GL045922, 2010.

Mansilla, G. A.: Ionospheric storm effects at the equatorial anomaly, Int. J. Geom. Aero., 4, 209-214, 2003.

Martinis, C., Eccles, J. V., Baumgardner, J., Manzano, J., and Mendillo, M.: Latitude dependence of zonal plasma drifts obtained from dual-site airglow observations, J. Geophys. Res., 108, 1129, doi:10.1029/2002JA009462, 2003.

Martinis, C. R., Mendillo, M. J., and Aarons J.: Toward a synthesis of equatorial spreadFonset and suppression during geomagnetic storms, J. Geophys. Res., 110, A07306, doi:10.1029/2003JA010362, 2005.

Mukherjee, G. K. and Shetti, D. J.: Plasma drift motion in F region of ionosphere using photometric nightglow measurements, Ind. J. Radio Space Phys., 37, 249-257, 2008.

Mukherjee, G. K., Carlo, L., Mahajan, S. H., and Patil, P. T.: First results of all-sky imaging from India, Earth Planet Space, 50, 119-127, 1998.

Nade, D. P., Sharma, A. K., Nikte, S. S., Ghodpage, R. N., Patil, P. T., Rokade, M. V., and Vhatkar, R. S.: Occurrence of F-Region Plasma Bubble Over Low Latitude Station: Kolhapur, Proceedings of CARCAN-2012, Hyderabad, 21-22 December, 94-99, 2012.

Pimenta, A. A., Fagundes, P. R., Bittencourt, J. A., Sahai, Y., Gobbi, D., Medeiros, A. F., Taylor, M. J., and Takahashi, H.: Ionospheric plasma bubble zonal drift: A methodology using OI $630 \mathrm{~nm}$ allsky imaging systems, Adv. Space Res., 27, 1219-1224, 2001.

Pimenta, A. A., Fagundes, P. R., Sahai, Y., Bittencourt, J. A., and Abalde, J. R.: Equatorial F-region plasma depletion drifts: lati- 
tudinal and seasonal variations, Ann. Geophys., 21, 2315-2322, doi:10.5194/angeo-21-2315-2003, 2003.

Rishbeth, H., Bauer, P., and Hanson, W. B.: Molecular ions in the F2 layer, Planet. Space Sci., 20, 1287-1293, 1972.

Sahai, Y., Aarons, J., Mendillo, M., Baumgardner, J., Bittencourt, J. A., and Takahashi, H.: OI $630 \mathrm{~nm}$ imaging observations of equatorial plasma depletions at $16^{\circ} \mathrm{S}$ dip latitude, J. Atmos. Terr. Phys., 56, 1461-1475, 1994.

Sahai, Y., Fagundes, P. R., Bittencourt, J. A., and Abdu, M. A.: Occurrence of large scale equatorial $\mathrm{F}$ region plasma depletions during geo-magnetic disturbances, J. Atmos. Sol.-Terr. Phys., 60, 1593-1604, 1998.

Sahai, Y., de Jesus, R., Fagundes, P. R., Selhorst, C. L., de Abreu, A. J., Tulasi Ram, S., Aragon-Angel, A., Pillat, V. G., Abalde, J. R., Lima, W. L. C., and Bitten-court, J. A.: Effects observed in the equatorial and low latitude ionospheric F region in the Brazilian sector during low solar activity geomagnetic storms and comparison with the COSMIC measurements, Adv. Space Res., 50, 1344-1351, 2012.

Sekar, R., Chakrabarty, D., Sarkhel, S., Patra, A. K., Devasia, C. V., and Kelley, M. C.: Identification of active fossil bubbles based on coordinated VHF radar and airglow measurements, Ann. Geophys., 25, 2099-2102, doi:10.5194/angeo-25-2099-2007, 2007.

Sinha, H. S. S., Rajesh, P. K., Misra, R. N., and Dutt, N.: Multi-wavelength imaging observations of plasma depletions over Kavalur, India, Ann. Geophys., 19, 1119-1131, doi:10.5194/angeo-19-1119-2001, 2001.

Sharma, A. K., Nade, D. P., Nikte, S. S., Ghodpage, R. N., Patil, P. T., Rokade, M. V., Vhatkar, R. S., and Gurubaran, S.: Occurrence of Equatorial Plasma Bubbles over Kolhapur, Adv. Space Res., online first, doi:10.1016/j.asr.2013.07.018, 2013a.

Sharma, A. K., Nade, D. P., Nikte, S. S., Ghodpage, R. N., Patil, P. T., Rokade, M. V., Vhatkar R. S., and Gurubaran, S.: Development of Fast Image Analysis Technique for All Sky Images, Current Science, accepted, 2013b.

Sobral, J. H. A., Abdu, M. A., Pedersen, T. R., Castilho, V. M., Arruda, D. C. S., Muella, M. T. A. H., Batista, I. S., Mascarenhas, M., de Paula, E. R., Kintner, P. M., Kherani, E. A., Medeiros, A. F., Buriti, R. A., Takahashi, H., Schuch, N. J., Denardini, C. M., Zamlutti, C. J., Pimenta, A. A., de Souza, J. R., and Bertoni, F. C. P.: Ionospheric zonal velocities at conjugate points over Brazil during the COPEX campaign: Experimental observations and theoretical validations, J. Geophys. Res., 114, A04309, doi:10.1029/2008JA013896, 2009.
Takahashi, H., Abdu, M. A., Taylor, M. J., Pautet, P.-D., de Paula, E., Kherani, E. A., Medeiros, A. F., Wrasse, C. M., Batista, I. S., Sobral, J. H. A., Gobbi, D., Arruda, D., Paulino, I., Vadas, S., and Fritts D.: Equatorial ionosphere bottom-type spread F observed by OI $630.0 \mathrm{~nm}$ airglow imaging, Geophys. Res. Lett., 37, L03102, doi:10.1029/2009GL041802, 2010.

Taori, A., Dashora, N., Raghunath, K., Russell III, J. M., and Mlynczak, M. G.: Simultaneous mesosphere-thermosphereionosphere parameter measurements over Gadanki $\left(13.5^{\circ} \mathrm{N}\right.$, $\left.79.2^{\circ} \mathrm{E}\right)$ : First results, J. Geophys. Res., 116, A07308, doi:10.1029/2010JA016154, 2011.

Taori, A., Jayaraman, A., and Kamalakar, V.: Imaging of mesosphere-thermosphere airglow emissions over Gadanki $\left(13.5^{\circ} \mathrm{N}, 79.2^{\circ} \mathrm{E}\right)$ first results, J. Atmos. Terr. Phys., 93, 21-28, 2013.

Taylor, M. J.: A Review Of Advances In Imaging Techniques For Measuring Short Period Gravity Waves In The Mesosphere And Lower Thermosphere, Adv. Space Res, 19, 616-676, 1997.

Terra, P. M., Sobral, J. H. A., Abdu, M. A., Souza, J. R., and Takahashi, H.: Plasma bubble zonal velocity variations with solar activity in the Brazilian region, Ann. Geophys., 22, 3123-3128, doi:10.5194/angeo-22-3123-2004, 2004.

Vlasov, M. N., Nicolls, M. J., Kelley, M. C., Smith, S. M., Aponte, N., and Gonzalez, S. A.: Modeling of airglow and ionospheric param-eters at Arecibo during quiet and disturbed periods in October 2002, J. Geophys. Res., 110, A07303, doi:10.1029/2005JA011074, 2005.

Weber, E. J., Buchau, J., and Moore, J. G.: Airborne Studies of Equatorial F-Layer Ionospheric Irregularities, J. Geophys. Res., 85, 4631-4641, 1980.

Yao, D. and Makela, J. J.: Analysis of equatorial plasma bubble zonal drift velocities in the Pacific sector by imaging techniques, Ann. Geophys., 25, 701-709, doi:10.5194/angeo-25-701-2007, 2007. 